\title{
La administración de la precariedad y la flexibilidad como oportunidad Una etnografía de la producción local de jeans en Tlaxcala
}

\section{Janeth Rojas Contreras ${ }^{1}$}

${ }^{1}$ El Colegio de Tlaxcala, A.C. Tlaxcala, México ORCiD: 0000-0002-1775-7670

Correo electrónico: rojasc.janeth@gmail.com
Recibido

septiembre de 2019

Aceptado

junio de 2020

doi: 10.34096/cas.i52.7008

\section{Resumen}

Este artículo tiene por objetivo mostrar, desde un abordaje etnográfico, a los productores de pantalones de mezclilla en San Mateo Ayecac, Tlaxcala, México, como sujetos rurales que administran su propia precariedad y valoran en la flexibilidad una oportunidad para generar negocios productivos por cuenta propia, haciendo uso de los recursos inmediatos: tierras de cultivo, viviendas y relaciones de confianza que les permiten generar un tipo de economía subalterna, en la cual ellos asumen la figura de dueños y trabajadores; a la vez, lo flexible y lo precario son transversales a su estilo de vida, al proceso de socialización y a las condiciones y organización del trabajo. Emergen como nuevos sujetos rurales de los poros del capitalismo neoliberal, como población excedente y, al mismo tiempo, responsables de su propia sobrevivencia y manutención.

The administration of precariousness and flexibility as an opportunity. An ethnography on the local production of jeans

\footnotetext{
Abstract

This article aims to show, from an ethnographic approach, the producers of jeans in San Mateo Ayecac, Tlaxcala, Mexico, as rural subjects who manage their own precariousness and see flexibility as an opportunity to generate productive businesses on their own, making use of immediate resources: farmland, housing and relationships based on trust that allow them to create a type of subordinate economy, where they take on the figure of owners and workers at the same time; flexibility and precariousness are transversal to their lifestyle, the process of socialization and working conditions and organization. That is, they emerge as new rural subjects from the pores of neoliberal capitalism, as surplus population and, at the same time, responsible for their own survival and maintenance.
}

\section{Palabras clave}

Administración de la precariedad; Flexibilidad; Recursos; Sujetos rurales; Jeans

\section{Key words}

Precarity management; Flexibility; Resources; Rural Subjects; Jeans 


\section{A administração da precariedade e a flexibilidade como uma opor- tunidade. Uma etnografia sobre a produção local de jeans}

\section{Resumo}

Palavras-chave

Gestão da Precaridade; Flexibilidade; Recursos; Temas rurais; Jeans
Este artigo tenta mostrar, a partir de uma abordagem etnográfica, os produtores de jeans em San Mateo Ayecac, Tlaxcala, México, como sujeitos rurais que gerem sua própria precariedade e valorizam, através da flexibilidade, uma oportunidade de gerar negócios produtivos por si próprios, fazendo uso de recursos imediatos: terras agrícolas, habitações e relações de confiança que lhes permitem gerar um tipo de economia subordinada, onde assumem a figura de proprietários e trabalhadores. Ao mesmo tempo, a flexibilidade e precariedade é transversal ao seu estilo de vida, ao processo de socialização e às condições e organização do trabalho. Ou seja, emergem como novos sujeitos rurais dos poros do capitalismo neoliberal, como população remanescente e, ao mesmo tempo, responsáveis pela sua própria sobrevivência e manutenção.

\section{Introducción}

Desde una perspectiva etnográfica se aborda la forma en que el capitalismo neoliberal incorpora a los espacios y sujetos rurales como mano de obra barata, inmersos en condiciones de precariedad y flexibilidad, frente a un contexto de retraimiento de las actividades agropecuarias motivado por las constantes crisis del campo. Se presenta el caso de una localidad ubicada al suroeste de Tlaxcala, México, donde, desde hace 40 años, las familias completas se dedican al diseño, producción y venta de pantalones de mezclilla a partir de un modelo de trabajo de fragmentación local, donde los diversos productores comparten el ensamble y tratamiento de los mismos lotes de jeans, como una expresión de la economía subalterna, generada desde la propia invención de las personas para sobrevivir con sus escasos medios.

Infiero que esta capacidad para configurar un trabajo textil de carácter industrial por cuenta propia tiene que ver con dos estrategias de sobrevivencia imbricadas: administrar la propia precariedad y entender la flexibilidad como una oportunidad, en un contexto donde predominan el desdibujamiento del Estado y la capacidad del capitalismo neoliberal para producir población excedente sin acceso a ningún derecho laboral, ni a la seguridad social ni a la certidumbre salarial.

Para los sujetos rurales, vivir en la precariedad y en la flexibilidad sucede como una condición histórica matizada por coyunturas y proyectos de carácter político y económico que los inducen a tomar decisiones. Uno de estos momentos puede observarse en las iniciativas textiles de los ayequenses. Copiaron los modelos (ritmos y organización) de trabajo de las grandes industrias, encarnaron las lógicas neoliberales y, al encontrarse excluidos del capital, aprovecharon ciertos recursos internos, como la venta de tierras de cultivo, las viviendas para montar talleres y las redes de confianza de parentesco y vecinales para conseguir mano de obra. Se puede decir que tanto la precariedad como la flexibilidad son la arena donde los ayequenses han podido sobrevivir y emerger como nuevos sujetos rurales. Biográfica y cotidianamente experimentan vivir y pensar desde lo flexible y lo precario, tanto en los espacios de trabajo, como en los procesos de socialización y subjetivación. 
Este trabajo obedece a una investigación más amplia realizada entre los años 2015 y 2018. En el proceso etnográfico se utilizaron algunos métodos como la observación participante, entrevistas en profundidad, así como una encuesta realizada en el 2015 a 218 hogares de las localidades que comprenden al municipio de Tepetitla de Lardizábal, en el marco del proyecto PAPIIT IA300316 a cargo de la Dra. Paola Velasco (Instituto de Investigaciones Antropológicas-Universidad Autónoma de México [IIA/ UNAM]). Debido a las condiciones de informalidad y, en algunos casos, al tratamiento de mercancías apócrifas, la etnografía se convirtió en el medio privilegiado para obtener información en voz de los diversos productores, tianguistas, agricultores, y para acceder a los espacios y dinámicas de los diferentes talleres y viviendas que regularmente no son mostrados a quienes están fuera del circuito de producción y comercio de prendas de mezclilla. Los nombres presentados en las entrevistas son ficticios para proteger la identidad de los interlocutores.

\section{Una forma de beneficiarse de la precariedad y la flexibilidad en el capitalismo neoliberal}

Los escenarios rurales son un enclave para comprender los retos que enfrentan las poblaciones contemporáneas ante un contexto económico dominado por la flexibilidad y la precariedad. Ambos elementos han estado presentes históricamente en el sector agropecuario, en la pluriactividad, entendida como "la combinación de distintos quehaceres e ingresos" (Arias, 2009, p. 174), y en un estilo de vida modelado por el manejo y la posesión mínima de recursos, dos condiciones que muestran la capacidad de las personas para ser dúctiles en condiciones de una aparente carencia (Salas, Rivermar y Velasco, 2011). Sin embargo, en el contexto del neoliberalismo, los sujetos rurales ampliaron sus nociones sobre el trabajo precario y flexible al incorporarse en empresas con una alta capacidad de volatilizar los contratos, desechar la mano de obra (Cuevas, 2015) y disminuir las posibilidades de inserción en procesos de mercado con condiciones de seguridad social, derechos laborales y protección estatal (Harvey, 2015).

Esta "nueva" manera de experimentar la precariedad y la flexibilidad deviene de un proceso de intervención de capital extranjero, con el asentamiento y traslado de la industria maquiladora (Douglas y Hansen, 2003) hacia los espacios locales, donde un segmento de la población rural se incorporó a un modelo de trabajo regido por "la descomposición o parcialización en operaciones simples y estandarizadas" (De la Garza, 2006, p. 31), la variación del volumen en la producción, costos, horarios, rotación de personal y la inexistencia de contratos laborales.

Bajo estas condiciones, los sujetos rurales son captados por una economía de carácter global y por las fluctuaciones del mercado, que les confieren un margen de acción limitado (Salas y Velasco, 2013). A estos sujetos se les extrae su valor como fuerza de trabajo, productores y consumidores. Asimismo, sus saberes, territorio y recursos naturales son absorbidos por el capitalismo global y convertidos en mercancías. Son sujetos atravesados por un proceso selectivo capitalista, transitan entre las filas del trabajo activo y las de la población excedente (aquella que es total o temporalmente desempleada o subempleada) y afrontan las contradicciones generadas por el capitalismo en el nivel local, el cual se presenta con un papel acumulativo y generador de riqueza que, desde el mismo terreno, excluye y desata mecanismos de generación de miseria (Osorio, 2010).

En medio de esta economía de incertidumbre, las personas encuentran arenas de negociación y acción, aprovechan los procesos de capital y generan estrategias para beneficiarse de su condición. Cuando son trabajadores activos, encuentran la forma de "robarse una oportunidad" (Prentice, 2015, p. 2): utilizan los recursos de los espacios 
fabriles, de donde sustraen conocimiento y copian el modelo de los procesos organizativo y productivo, así como el uso, tipos y estilos de insumos, para ponerlos en práctica una vez que sean desechados como asalariados; y cuando se convierten en población excedente, buscan acomodo para sobrevivir y percibir ingresos dentro de la red de la economía informal, mediante la incursión en trabajos por cuenta propia en los sectores secundario y de servicios, y en algunos casos, con los conocimientos acumulados durante la fase de trabajadores activos.

En cualquiera de las dos situaciones, los sujetos rurales se convierten en gestores y operadores de su propia sobrevivencia y manutención, y emplean recursos mínimos o limitados para la reproducción de diversas prácticas sociales como el consumo, el trabajo, la salud, la diversión, estudiar, habitar y alimentarse. Aprovechan esta condición como una arena para administrar la propia precariedad y, al mismo tiempo, enfatizan la flexibilidad como una facilitadora de nuevas oportunidades.

Sostengo que administrar la propia precariedad implica idear estrategias para capitalizarse a sí mismo, aprovechando la apertura de mercados de trabajo y consumo. Los sujetos rurales toman los modelos de funcionamiento de los grandes corporativos, tanto en la organización del trabajo como en la producción, para integrarse en las relaciones de mercado encarnando ellos mismos el papel de productores-trabajadoresconsumidores mediante la creación de pequeñas empresas, casi siempre de carácter familiar. Incorporan de manera intensiva y extensiva diversas esferas y espacios de la vida cotidiana, así como tiempos, prácticas sociales y procesos psíquicos a las lógicas de la producción capitalista (Robinson, 2013), con todo lo que esto implica: reproducir, legitimar y perpetuar voluntariamente las condiciones de vulnerabilidad y fragilidad que predominan en las empresas dominantes, pero desde sus espacios locales.

Respecto de la flexibilidad como oportunidad, esta es entendida en los términos expuestos por Carla Freeman (2007) en sus estudios en el Caribe, donde logra visualizar que constituye la "piedra angular del neoliberalismo"; la considera un sistema para la autoinvención y el autodominio de los trabajadores que logran emerger como pequeños empresarios o emprendedores, desafiando la noción de que el capitalismo se realiza monolíticamente dominado por los mercados globales. Freeman deja ver un doble sistema de flexibilidad: uno derivado de los discursos y prácticas nacidos en los corredores del poder capitalista, y otro que emerge desde políticas de oposición entre la población subalterna (Freeman, 2007).

La capacidad de aprovechamiento de la precariedad y de la flexibilidad para ganarse la vida puede apreciarse en el caso de los productores de pantalones de mezclilla de la localidad de San Mateo Ayecac, ubicada en la región sur de Tlaxcala, México, quienes por medio de la incursión en el mercado emergente de la ropa de mezclilla han encontrado un nicho de producción y comercio idóneo para obtener ingresos e incluso para sostener parte de las actividades agropecuarias que aún prevalecen. Han construido una economía subalterna propia de grupos que operan en la informalidad y al margen del trabajo ofertado por corporativos trasnacionales, así como de las normas institucionales recaudatorias.

\section{El uso de recursos internos para trabajar en la producción de jeans en San Mateo Ayecac}

San Mateo Ayecac pertenece al municipio de Tepetitla de Lardizábal, Tlaxcala, colinda con las localidades de Villa Alta (al norte), Guadalupe Victoria (al este), la Cabecera municipal (al sur) y al oeste con la localidad de San Baltazar Temaxcalac, ubicada en el municipio de San Martín Texmelucan, Puebla. En los índices de la Secretaría de 
Desarrollo Social (2017) está catalogado con un promedio de pobreza bajo, el nivel educativo de su población es de 9,5 años de escolaridad. Aunado a esto, en los registros censales se contabilizan 16 negocios relacionados con la industria textil, sin embargo, se tiene conocimiento de que en las 890 viviendas habitadas en la localidad (INEGI, 2014) existen o han existido, de forma permanente o temporal, actividades productivas relacionadas con la producción de pantalones de mezclilla.

La actividad textil comenzó en la década de 1970; se trataba de jóvenes que dividían su tiempo productivo entre el trabajo agrícola en la siembra de hortalizas, legumbres y maíz, $y$ las dinámicas de movilización laboral hacia las ciudades de México y Puebla, para integrarse en diversos oficios como vendedores informales, en la construcción y como mano de obra en fábricas, principalmente de textiles. En el caso de los precursores del trabajo con la mezclilla en la localidad, también incursionaron como aprendices de sastre, quienes ubicaron el pantalón como una prenda nodal para el vestuario masculino y de hechura relativamente sencilla, que prometía una producción y venta seguras. Inicialmente, tomaban prestados los moldes de papel de sus lugares de trabajo, o bien utilizaban pantalones que llevaban a sus casas para descoserlos y calcar los trazos de cada pieza sobre tela de tergal y pana.

El nuevo medio de sobrevivencia consistía en hurtar habilidades de costura, observar cuidadosamente y con astucia (Prentice, 2012) a los sastres y confeccionistas experimentados, para luego intentar las técnicas por sí mismos. Gradualmente, esta práctica fue socializada por otro grupo de jóvenes que se acercó a estos aprendices de sastrería con un doble propósito: afianzar los lazos de amistad y aprender el nuevo oficio. En otros casos, los principiantes pedían la compañía de algunos parientes, vecinos y amigos para instruirles y conformar equipos de trabajo mientras ellos mismos asumían los papeles de dueño y trabajadores.

Estos primeros intentos de sobrevivencia por cuenta propia representaron una aproximación al espíritu del emprendimiento en pos de conseguir los objetivos de la autoinvención creativa, prescindir de los jefes y crear pequeñas empresas apoyadas en lazos familiares en el ámbito del hogar (Freeman, 2007), pero con una organización de ensamble compleja y fragmentada en talleres y trabajadores. Una década después, ante la proliferación de las modas y la popularización de la ropa de mezclilla en los medios de comunicación y en los espacios de comercio, la tela denim representó un nicho productivo prolífico, y en la actualidad está inserta en diversos espacios de la vida local, desde la identidad generacional, de clase y género, así como en las actividades creativas de diseño e invención de modas regionales. También se incorporó a las significaciones sobre el prestigio y el estatus de los ayequenses. Como objeto de trabajo, está presente en sus espacios de convivencia, habitación y producción, así como en los recursos naturales y en sus cuerpos como un bien y como un factor contaminante que produce problemas de salud a los productores (Velasco, 2017).

Para desarrollar la recién nacida industria textil, los jóvenes precursores aprovecharon los "escasos" recursos internos con los que contaban al interior de la localidad (Arjona y Checa, 2006): tierras de cultivo, vivienda y lazos de confianza, para afianzar tanto las manos como los espacios de trabajo.

\section{a) Tierras de cultivo}

En primer lugar, estrecharon la dependencia entre la actividad textil y el campo a partir de la venta de tierras de cultivo para costear la adquisición de las primeras máquinas de coser e insumos, y destinaron una fracción de estos terrenos para edificar viviendas. Algunos elementos - como las constantes crisis del campo, los procesos de contaminación ambiental en la región y la liberación de las tierras de cultivo al 
mercado- facilitaron que los ayequenses aminoraran la actividad agrícola y se inclinaran por el trabajo en la producción de prendas de vestir.

El municipio donde se ubica San Mateo Ayecac formó parte del conjunto de haciendas productoras de trigo ubicadas en la zona lacustre del valle. La región a la que pertenece era conocida en épocas coloniales como la Ciénaga de Tlaxcala, pero a inicios del siglo XX fue objeto de la política de Estado que tenía por objetivo desecarla, mediante el drenaje de las aguas de los ríos Atoyac y Zahuapan con la finalidad de abrir nuevos territorios a la agricultura (Paleta, 2014). Hacia la década de 1960 -periodo en que se intensificó la transformación de estos humedales (Velasco, 2014a)-, en Tepetitla de Lardizábal, los productores comenzaron a sembrar verduras y legumbres como parte de una serie de proyectos de modernización del campo, mediante la capacitación de los agricultores, la introducción de medios de carga y transporte y la dotación de maquinaria, semillas y fertilizantes (González, 2008b).

La bonanza del cultivo de verduras perduró por poco tiempo; gradualmente, los productores enfrentaron un acceso desigual a las capacitaciones sobre el manejo de fertilizantes y el cuidado y control de los cultivos; únicamente los agricultores que poseían una o más hectáreas recibieron tractores y abono de los programas federales y estatales, el resto de los productores tenían que comprarlos por su cuenta o pedirlos prestados a los beneficiarios. Además de esto, tuvieron que lidiar con la contaminación de los afluentes cercanos (canales, zanjas y ameyales) que nacen al paso del río Atoyac y reciben los desechos de los corredores y parques industriales como el Ixtacuixtla (donde se produce cerámica, productos automotrices, productos en aerosol, alimentos y otros) asentados en la región Puebla-Tlaxcala, aunado a la industria petroquímica establecida desde 1960 y considerada como el principal contaminante de la región.

Las respuestas y experiencias de los agricultores en torno a la contaminación del agua $y$, por ende, de sus tierras y hortalizas, fueron diversas. Mientras algunos optaron por renunciar a la labranza de estas tierras, "para evitar dificultades en la comercialización de sus productos" (Vallejo, 2016, p. 82) y sanciones en el mercado local y regional y dedicarse a la actividad textil; otros pocos continúan cultivando y buscando espacios comerciales en la central de abastos de la Ciudad de México y en mercados locales donde regularmente les rechazan el producto o se lo compran a bajo costo. Además, el proyecto neoliberal, a partir de la reforma agraria (entre los años 1991 y 1992) permitió, mediante mecanismos jurídicos, el cambio de estatus de las tierras ejidales y preparó al campo para los nuevos procesos de acumulación capitalista (Velasco, 2014b).

Esta trayectoria agrícola muestra cómo el campo y las actividades agropecuarias han estado presentes en el paisaje y en la búsqueda de sobrevivencia de los sujetos rurales. Las tierras de cultivo son un recurso flexible que puede ser adecuado a las necesidades emergentes de sus propietarios, ya sea cultivándolas, cambiando su uso (de agrícola a habitacional o comercial) o preservándolas para enfrentar posibles crisis económicas o emprendimientos futuros. En la actualidad, los productores de jeans financian la siembra de maíz y verduras, la floricultura a cielo abierto, la adquisición de semillas, fertilizantes, la compra de agua y la crianza de animales de traspatio, y destinan una cantidad promedio de 721 dólares por siembra, pese a que frecuentemente no obtienen ganancias o tampoco recuperan este gasto. Esto sucede, en particular, en aquellas familias que tienen algún integrante dedicado a la producción agrícola, regularmente, personas mayores entre los 54 y 70 años de edad.

En la historia económica y social de los ayequenses, las tierras de cultivo han sido un medio de sobrevivencia para diversas generaciones; en la consolidación de sus proyectos de vida son consideradas como un soporte para el desarrollo de ciertas aspiraciones, compromisos y deseos individuales y familiares, por ejemplo, la construcción de nuevos 
talleres o la ampliación de estos. Los productores de mezclilla han encontrado formas de vivir directa e indirectamente de la tierra y de asegurar que esta siga siendo un recurso de acceso inmediato para ellos y sus hijos, aun con los problemas económicos, políticos y ambientales que esto conlleva.

\section{b) Viviendas}

En un ambiente de precariedad, uno de los recursos internos más factibles para emprender una nueva actividad económica de forma segura, discreta y al menor costo es la vivienda. Esta cambia, al igual que sus habitantes cuando atraviesan un proceso de reconversión productiva, entendido como el tránsito de un estilo de vida y actividad de tipo agrícola hacia uno industrial (Vallejo, 2016). Las casas asumen esta característica: van transformándose y adecuándose a las necesidades de sus habitantes, reconvierte sus prácticas de convivencia íntimas y familiares por actividades productivas de carácter económico; donde antes había un espacio doméstico bien delimitado, hoy existe moblaje, maquinaria y material de trabajo textil en uso o en resguardo.

La reconversión del uso de la vivienda es parcial; se presenta como una frontera difusa entre los usos y la organización de la casa como espacio doméstico y laboral, en la medida que la familia se mueve entre la reproducción de roles de parentesco y el papel de productores o trabajadores. Al interior de las viviendas es notable la presencia de cúmulos de mezclilla, hilos y tijeras sobre los muebles, en los patios y corredores del hogar, así como en medios de transporte como triciclos, bicicletas o motocicletas estacionados dentro de las casas.

Algunos de estos talleres, principalmente de costura, fueron improvisados sobre habitaciones ya existentes en las viviendas; en otros casos, en la medida en que los productores incrementaron sus ingresos, pudieron construir cuartos para ocuparlos como unidades productivas, o bien los edificaron en forma de bodega como un anexo de la vivienda. Las casas ayequenses expresan una relación denominada por Kellet y Tipple (2000) como simbiótica, debido a que muchas familias no tendrían una vivienda si no llevaran adelante sus actividades textiles, y muchas de estas actividades no podrían llevarse a cabo sin el uso de la vivienda como sitio de producción.

En otros casos, durante la etapa de arranque de la producción de jeans no fue necesario improvisar talleres, pero se utilizaron ciertos espacios de las casas para ampliar el tratamiento de la mezclilla, por ejemplo, el lavado casero, tal como relata uno de los precursores de esta actividad:

Los primeros procesos eran de tina, para suavizarlos poníamos agua caliente y Suavitel, ${ }^{1}$ después nos metíamos en la tina para aplastar los pantalones con los pies, luego los poníamos a secar en los tendederos de la casa, dependiendo del sol, tardaban en secarse. Cuando queríamos hacer un proceso de deslave, íbamos tanteando cantidades de cloro y pedazos de vidrio para que el pantalón se destiñera según nuestro gusto. Luego los planchábamos, antes no se usaban planchas industriales, teníamos nuestras planchitas sencillas de carbón o de luz. (Entrevista a Jacinto, lavandero, San Mateo Ayecac, mayo de 2016)

Este proceso cambió en 1990, cuando la empresa de maquila denominada Eurocolor se asentó en la localidad y empleó a jóvenes ayequenses, que aprendieron diferentes procedimientos o técnicas de diseño como el lijado, engrapado y deslavado con distintos materiales, la mezcla de sustancias químicas y el manejo de colorantes para teñir o decolorar la mezclilla. Sin embargo, al ser expulsada de la localidad -a petición de los vecinos, por la contaminación que producía y la falta de pago a los trabajadores-, los jóvenes optaron por ofrecer los conocimientos adquiridos en las lavanderías locales
1. Es una marca comercial de un suavizante de telas para uso doméstico. 
que comenzaban a crecer, con la promesa de hacerlas competitivas y mantener la producción local al ritmo de las modas emergentes.

En la actualidad, tanto las actividades dirigidas a la elaboración de jeans como la organización de la producción, los salarios de los trabajadores y el proceso de ensamble se han complejizado, debido a que, además de la lavandería y la costura, en las viviendas se han creado negocios de venta de tela de mezclilla nacional y "china" o de retazos de lienzos para la elaboración de las bolsas blancas internas del pantalón, así como de pantalones de bajo costo, pedrerías y mercerías; también han montado talleres de corte, bordadoras, ojaladoras, planchadurías y de lijado. Algunas familias poseen solo un tipo de taller; otras son propietarias de dos o más (cada uno dedicado a diferentes labores de esta producción textil). En algunos casos, además, poseen algunos de los comercios anteriormente mencionados. Respecto de ciertos grupos familiares precursores de la actividad en la localidad, han tenido casi todos los tipos de talleres, pero los heredaron a los hijos y nietos, o incursionaron en actividades emergentes como el trabajo de bordado, que en la localidad se inició en el año 2011, y que es más redituable y menos usual que la costura. También existen familias sin estas posesiones, algunas de las cuales se emplean en los talleres o realizan trabajo a domicilio quitando los excesos de hilo o realizando alguna costura sencilla.

Los tipos y tamaños de los talleres son diversos; en cierta forma, dependen del tamaño de la vivienda; por ello, algunos reproducen solo una actividad, como planchar, bordar, cortar las piezas de tela, coser o pegar pedrería; en otros casos, combinan dos o más de estas labores. Algunos funcionan con cuatro o cinco trabajadores de la misma familia y/o externos a esta, mientras que otros cuentan con más de ocho integrantes. En el caso de los que tienen mayor capacidad, trabajan hasta veinte personas.

Debido a que estos espacios de producción están dentro de las viviendas, la mayoría opera en la informalidad, por ello, las familias niegan tanto la existencia de estos lugares como la dedicación a la actividad textil a los censos económicos y poblacionales, así como a las autoridades. Sin embargo, se estima que aproximadamente el $70 \%$ de estas personas trabaja en alguna de las fases del ensamble de jeans, al menos el 83,7\% de la población entre los 21 y 40 años de edad se dedica a la costura. En esta actividad trabajan en conjunto padres, madres e hijos de diversas edades, un 50,6\% de hombres y un $49,4 \%$ de mujeres; mientras que en las lavanderías, el 71,4\% de trabajadores son hombres jóvenes.

La producción que realizan estas familias dista de la maquila para empresas medianas o corporativas trasnacionales. Localmente se consideran como fabricantes independientes que trabajan para: a) "patrones": llaman de este modo a los comerciantes informales de ropa de mezclilla que provienen de diferentes estados de la República Mexicana, principalmente del Centro Histórico de la Ciudad de México; b) el propio dueño de la casa-taller, quien además de comprar la tela y participar en el proceso productivo tiene como propósito vender los jeans; c) en forma colaborativa con los talleres vecinos, con la finalidad de complementar la siguiente fase del ensamble o cuando no se cuenta con la maquinaria o trabajadores suficientes para desahogar el trabajo; d) empresas medianas de tiendas de ropa que someten las piezas ensambladas a pruebas de calidad como el número y medida de cada puntada y la distancia entre cada una de las líneas de costura. Si bien los ayequenses son productores con larga experiencia, la mayoría de las prendas que realizan no observan esta rigidez; y e) trabajo a domicilio.

$\mathrm{Al}$ interior de las viviendas es posible observar la manera en que tanto los integrantes de la familia como los trabajadores externos a esta laboran en cadena, por ejemplo: 1) Martha cose la bolsa blanca y realiza la costura "over" que abraza las orillas de la tela para evitar que esta se deshile; 2) su esposo, Esteban, dueño del taller, empalma "la 
vista", esto es, une las dos partes frontales del pantalón por medio de la costura del cierre; 3) el vecino, Alberto, trabaja en la cara trasera de la prenda, "engargola la bata" (corte en forma de triángulo invertido que va a la altura de la cadera y se usa en los jeans de modelo vaquero) y cose las bolsas traseras y las etiquetas "de bandera" (pequeñas etiquetas que sobresalen en uno de los costados de la bolsa derecha, como en el caso de la marca Levi's); 4) la comadre, María, "overlea"2 las costuras de la entrepierna y los extremos; 5) su esposo, Julio, cose la traba o presilla (pieza en forma de tira larga doblada por la mitad que rodea la cintura del pantalón); 6) Brenda, la hija de María y Julio, elabora la pretina (pequeñas tiras dobladas, cosidas en forma vertical a la presilla); y 7) Adrián, novio de Brenda, realiza los dobladillos inferiores. Mientras esto sucede, el hijo pequeño de Esteban y Martha "forma" los pantalones (el niño ordena cada una de estas piezas y las circula entre los costureros, también clasifica las prendas terminadas por tallas).

Al terminar, Esteban traslada los jeans a la lavandería, donde son sometidos a procesos de lavado, suavizado, decoloración o desgaste, según el diseño solicitado. Posteriormente, el lote se envía a las planchadurías; después, a los talleres de bordado o pedrería y de ojales; más tarde, regresa al taller de costura, donde le son cosidas las "etiquetas coco" (etiquetas de cartón con el nombre y logo comercial del pantalón). En los siguientes días, cada prenda es embolsada para ser vendida en algún negocio propio o tianguis de la región Puebla-Tlaxcala, o bien es entregada al "patrón".

El proceso de colaboración entre talleres-viviendas replica un modelo de fragmentación local, donde cada conjunto familiar con sus respectivos trabajadores asume una fase específica de la producción. Esta organización es una representación microeconómica de la deslocalización industrial caracterizada por la segmentación del proceso productivo en fases realizadas en distintos establecimientos y por la provisión de trabajo de subcontratación y a domicilio (Caravaca, 1991 en Méndez, 1994).

El encargado o dueño de la casa-taller es el responsable de asignar la cantidad de piezas con base en las tareas que cada trabajador sabe hacer y de acuerdo con el orden en que se incorporan al trabajo durante el día. Quienes desean obtener más ingresos comienzan o culminan la jornada durante la madrugada, debido a que el pago es a destajo. Cotidianamente, es común que las y los trabajadores lleven consigo un pequeño cuaderno para anotar el número de piezas que ensamblan por día. Los dueños también realizan anotaciones que registran la contabilidad de los costos, ganancias, pagos y deudas. Mientras los trabajadores externos a la familia reciben pagos semanales, los integrantes del núcleo familiar como las esposas e hijos reciben el dinero que les corresponde como una gratificación o incentivo, el cual es reinvertido en el taller, en los gastos domésticos y en el consumo de objetos de uso personal.

Los distintos talleres tienen la misma importancia sin considerar la cantidad de maquinaria o trabajadores con que cuentan, porque de alguna manera todos contribuyen a la terminación de los mismos lotes de pantalón. Empero, existe una estratificación de trabajadores determinada por el conocimiento especializado sobre las máquinas y costuras. Por ejemplo, los aprendices y quienes "forman" el pantalón reciben pagos de $\$ 200.00$ mexicanos semanalmente, quienes hacen costuras over ganan $\$ .0,30$ por pieza (es la actividad más común), los trabajadores que cosen las partes delantera y trasera obtienen $\$ 6.00$ por pantalón (solo algunas manos saben hacer este trabajo). Respecto de la producción, varía con base en el tamaño de cada taller y la cantidad de máquinas disponibles, pero regularmente en los espacios de costura se producen entre 500 y 800 pantalones por día, mientras que en las lavanderías manejan al menos 3000 pantalones diariamente, debido a que tanto las máquinas procesadoras como las lavadoras pueden tratar decenas de pantalones al mismo tiempo.
2. Diversas funciones y tareas, así como el manejo de ciertas máquinas y sustancias son referidas por los trabajadores en forma de verbo, como: "overlear" y "cerrar" (uso de las máquinas de coser overlock y cerradora); "pretinar" y "presillar" (confeccionar la pretina y la presilla); "potasear" (aplicar permanganato de potasio); "formar" (ordenar los pantalones por talla o por piezas). Esta situación puede representar un problema para los ayequenses cuando, de manera temporal, se insertan laboralmente en maquilas formales poblanas o tlaxcaltecas, donde las referencias a estas actividades son diferentes, así como el nombre de las herramientas y los procesos de trabajo. 
Las viviendas, además de ser un recurso para el desarrollo de las actividades de producción textil, se convierten en sitios donde los trabajadores y sus familias organizan eventos y festividades de la vida local. El trabajo dentro de la vivienda provee ciertos beneficios, como realizar un solo gasto en servicios básicos, disminuye tiempos muertos, los trabajadores tienen al alcance la mayoría de los objetos laborales y domésticos que necesitan y, en el nivel subjetivo, experimentan mayor comodidad y sensación de seguridad al tener al conjunto familiar a la vista.

\section{c) Lazos de confianza}

El tercer recurso interno de los productores ayequenses, para el montaje y funcionamiento de la industria local, es el tejido de relaciones sociales y económicas construido entre parientes y vecinos. Este funciona sobre las bases de la confidencialidad y la confiabilidad en el otro, tanto en la reproducción del trabajo por roles de género como en los tratos y contratos de palabra.

De acuerdo con Frances Rothstein (1986), las redes de parentesco y las familiares son similares, en algunos aspectos, a las de los campesinos, pero enmascaran diferencias importantes, una nueva faz de la familia es el empleo flexible, la participación de las mujeres desde una figura proletarizada; se evidencian las diferencias generacionales, asimismo, se nota una creciente preocupación e ilusión de consumo que, de a poco, va cambiando la apariencia de las viviendas y de las personas.

Con base en información recabada en la localidad, es posible saber que existe una reminiscencia de la organización familiar en torno al trabajo agropecuario que opera al interior de los talleres, así como de los vínculos comunitarios que han caracterizado a las sociedades rurales. Cada integrante mantiene roles, formas y fines de participación en la familia como se hacía antes del arribo de la industria textil.

En mis tiempos no había cosas como ahora, las muchachas nos dedicábamos al puro hogar, llevábamos la comida a la milpita, y los muchachos eran diferentes, siempre andaban ayudando, eran buenos campesinos, pero ahora ya no les gusta porque el campo es duro, el sol es fuerte y te acaba. Ahora que ya se dedican a puros talleres, hasta las mujeres ahí andan con los esposos ayudándoles...ganándose sus centavos, bueno, hasta los niños chiquitos, se ganan un dinero. (Entrevista a Celia, habitante de San Mateo Ayecac, junio 2016)

Si bien existe una incorporación de mujeres y niños al trabajo textil, la participación de estas figuras continúa presentándose como ayuda familiar, en tanto los hombres ejercen el mando sobre la producción. Esto es evidente en la división del trabajo: los varones son dueños de los talleres, diseñan, investigan tendencias de moda, cortan la tela, cargan bultos, manejan las máquinas más grandes y pesadas, realizan las mezclas de sustancias químicas, controlan el pago y contratación de los trabajadores, deciden sobre los tiempos de aprendizaje e inserción de sus hijos en la costura o el manejo del taller, disponen del orden de las máquinas en el espacio de labor, realizan los tratos de trabajo con los "patrones" y deciden sobre la apertura o cierre de las unidades productivas, e incluso disponen de los créditos que las esposas solicitan a las microfinancieras.

Las mujeres son percibidas como una extensión de la mano de trabajo masculina: su labor es de carácter manual (coser, lijar, cortar los residuos de hilos, crear plantillas de pedrería, planchar); además, asumen la responsabilidad de las actividades domésticas, la crianza, cuidados y tareas escolares de sus hijos, así como la socialización del trabajo de estos. Los niños interiorizan su participación en la producción como parte de los deberes cotidianos. Desde los 5 o 6 años de edad aprenden el trabajo flexible como una actividad lúdica por la cual reciben pequeños pagos de 8 a 10 dólares semanales; 
al regresar de las escuelas, toman un tiempo para practicar en las máquinas de coser o para ayudar a sus padres con el acomodo de las piezas de mezclilla, llevan recados, realizan compras de emergencia en las mercerías o reciben los lotes de pantalones provenientes de otros talleres y, a medida que crecen, se involucran en tareas más complejas y adquieren mayores responsabilidades. El lugar y las tareas descritas que ocupan los integrantes de la familia son replicados cuando se emplean en los talleres de la parentela más amplia o de los vecinos.

Los precursores de la elaboración de jeans en la localidad extendieron la red de labor más allá del núcleo familiar, integraron a la mayor cantidad de allegados, a quienes habilitaron y emplearon como trabajadores. Lograron revestir los lazos locales, de parentesco y de vecindad, de un aspecto económico.

Los primeros que comenzaron con el taller fueron mi papá y su hermano, Rolando M. Mi papá aprendió con un sastre. Me contaba que su primera máquina fue una recta, él le enseñó a coser a muchos de por aquí, invitó a sus demás hermanos y dos de mis tías, por parte de mi mamá. Si tú ves, muchos de los talleres de por aquí están emparentados, yo digo que se fue haciendo la cadenita, porque tantito aprendía uno, luego veías que ya tenía una máquina en su casa, luego otra y así hasta que ya tenía su taller, luego los hijos seguían el mismo camino; veme a mí y a mis hermanas, todas tenemos varios talleres con nuestros maridos. Luego viene la gente para que le dé trabajo o porque no saben y quieren aprender, pero, cómo te diré, les enseñas y luego te dejan porque también quieren coser en sus casas. Antes nos iba mejor, pero ahora ya todos tienen taller. (Entrevista a Ofelia, productora de pantalones y dueña de una mercería, San Mateo Ayecac, mayo 2016)

La incorporación de familia y vecinos detonó y afianzó la proliferación de la actividad textil en cada una de las viviendas de la localidad. Si bien la primera intención de los precursores fue la sobrevivencia y crecimiento del taller propio, también había otro propósito: capacitar a los coterráneos para que tuvieran algún oficio que les permitiera sobrevivir y quedarse en el pueblo, como sucedía en otras localidades textileras aledañas. El resultado es exitoso, cada familia con su respectivo taller o negocio de comercio y conocimientos se sitúa en alguna fase del modelo de fragmentación productiva local y facilita la circulación de mercancías mediante la realización de trabajo en "deuda" (recibir el pago de las piezas tratadas una vez que el lote de pantalones sea vendido), el préstamo de material y la obtención de créditos de tela e insumos entre los negocios locales.

Los lazos de confianza, vecindad y parentesco se convierten en un recurso económico, ya que a partir de ellos, además del intercambio de servicios, el apoyo moral, la transmisión de saberes y la asistencia solidaria entre coterráneos (Adler, 1975), tienen lugar los acuerdos económicos y comerciales, las relaciones laborales y la competencia productiva entre pares, encaminadas al ingreso económico de la localidad (Arjona y Checa, 2006); proveen de mano de obra, permiten la organización de la red de trabajo tanto al interior de los talleres como entre estos. Al mismo tiempo, el alto nivel de confianza mutua que mantienen impide la detección de la actividad textil por parte de instituciones recaudatorias (Portes y Haller, 2005).

Los lazos de confianza también se sitúan en la conformación de alianzas y uniones de compadrazgo con los trabajadores y "patrones" externos a la localidad, con quienes, durante cuarenta años, los ayequenses han podido participar del circuito de producción y comercio informal entre Tlaxcala, San Martín Texmelucan -en Puebla-, y la Lagunilla, Izazaga, Tepito, La Merced, Circunvalación y Pino Suárez, en la Ciudad de México. Estas conexiones tienen su antecedente en el trabajo que los confeccionistas de vestido de la Cabecera Municipal de Tepetitla efectuaban para la comunidad libanesa en México, 
cuyos negocios se encontraban en el Centro Histórico del otrora Distrito Federal. Allí, extendieron nexos con otros proveedores y comerciantes que gradualmente fueron abordados por los productores ayequenses para ofrecer su trabajo y mercancías.

La confianza mutua en la responsabilidad y discreción sobre el manejo, traslado y comercio de la tela de mezclilla, de los jeans y de las etiquetas, así como el resguardo de los datos y lugares específicos donde se localizan tanto los talleres ayequenses como los domicilios y puestos de los vendedores de tianguis, aseguran la perpetuación de cada una de las actividades, fuera de la vista de las autoridades. Al mismo tiempo que refuerza la presencia de los "patrones", quienes visitan los talleres dos o tres veces por mes y demandan una constante renovación de estilos y diseños, tanto de costura como de lavandería, pedrería y bordados que, muchas de las ocasiones, son propuestos por los jóvenes de San Mateo Ayecac con base en el gusto local.

Retomando los tres recursos descritos, las tierras de cultivo, las viviendas-talleres y los lazos de confianza, es posible apreciar cómo los productores locales de jeans logran convertir la noción de precariedad y el trabajo flexible en una conveniencia. Los ayequenses permiten desmontar la idea de pasividad de los sujetos y clases subalternas, ya que se asocian, trabajan y reconocen en campos de poder (Gómez, 2008); y si bien están en constante tensión con empresas y marcas trasnacionales de jeans debido a la imitación de modelos y etiquetas, no pretenden proponer un nuevo orden en el cual ellos sean quienes manejen grandes cantidades de producción y dinero, sino afianzar su lugar en el orden hegemónico prevaleciente y echar mano de los recursos inmediatos para sobrevivir de acuerdo con sus posibilidades, saberes y habilidades.

Se puede decir que los productores locales de ropa de mezclilla son la expresión de un nuevo sujeto rural, y muestran que no han sido las grandes corporaciones trasnacionales de la industria textil quienes directamente exprimen la mayor cantidad de recursos al menor costo en aras de maximizar la productividad. Por el contrario, los productores de esta localidad tomaron la iniciativa de ajustarse al modelo político y económico del capitalismo neoliberal para poder sobrevivir, y se convirtieron en su propia mano de obra barata, al mismo tiempo que en los dueños, productores y consumidores de las mercancías producidas en la región, es decir, se transformaron en administradores de su propia precariedad.

\section{Flexibilidad y precariedad: un locus para la emergencia de nuevos sujetos rurales}

Este nuevo sujeto rural con habilidades industriales es producto de coyunturas y procesos específicos. Parafraseando a Roseberry (2014), los sujetos y sus contextos están formados de sedimentos históricos, de encuentros específicos previos y en curso entre poderes y circunstancias particulares. En el caso de Tlaxcala, la vocación textil existe desde la época de la colonia, con los obrajes de lana. Según Alba González (2008a), un tanto de esta producción se desarrollaba en las casas de los trabajadores con permiso de los dueños de obrajes, mientras otra parte sucedía de manera clandestina en viviendas donde los obradores construían sus propios telares caseros de pedal para fabricar ropa y tela.

Grosso modo, en la región donde se ubica San Mateo Ayecac, la economía y las actividades por cuenta propia han estado permeadas por la actividad textil. La fabricación de ropa ha sido generadora de fuentes de empleo, movilidad poblacional, desarrollo de infraestructura y cambios en la trayectoria del campo (Suárez, 2011). Por esta razón, ha sido uno de los elementos que, junto con la pluriactividad, la migración y el sector de servicios, han complejizado a los sujetos y a los espacios rurales contemporáneos. 
Aunque los productores ayequenses se integraron a la producción de prendas de vestir en un momento cumbre de atisbo del neoliberalismo, cada generación se amoldó a las exigencias e intensificación de este modelo político y económico; ellos mismos se convirtieron en una encarnación de los valores y lógicas neoliberales, es decir, se construyeron identitaria, psíquica, vivencial y productivamente a partir de la flexibilidad y la precariedad. Esto puede verse reflejado en tres aspectos nodales:

1.- En las condiciones de trabajo. Debido a la informalidad y a las relaciones de parentesco inmersas en el proceso productivo, existe nula posibilidad de generar contratos de trabajo, de regular la jornada laboral o de obtener prestaciones tales como la seguridad social. También predominan el riesgo y la contingencia frente a elementos contaminantes como la pelusilla y el tinte de la mezclilla, el fluir de agua mezclada con sustancias como el cloro, lijas, tinte índigo, etcétera; el peligro latente de sufrir accidentes con las máquinas y el material cortante; la posibilidad de un sobrecalentamiento y explosión de las calderas en el espacio de las lavanderías, aunado a situaciones de enfermedad producidas por una alimentación deficiente, largas posturas corporales sostenidas para realizar alguna de las actividades textiles, más la presencia de malestares corporales y, en casos severos, leucemias.

2.- En el estilo de vida. De acuerdo con Sttebbins (1997 en Dumont y Clua, 2015), este comprende varias dimensiones sociales: la manera en que los individuos obtienen los recursos necesarios para una actividad concreta, la forma de relacionarse con el mundo social y de organizar sus actividades, la definición de intereses sociales y el modo en que se identifican con una actividad. En este caso, los cuatro aspectos son atravesados por el trabajo en la producción y tratamiento de pantalones de mezclilla. Tanto las viviendas, como las dinámicas familiares, las relaciones comunitarias y el tiempo son absorbidos y disciplinados a la producción textil, donde los trabajadores permanecen hasta 15 horas diarias, seis o siete días a la semana. Aunque tener un trabajo por cuenta propia es percibido por los ayequenses como una forma de ser libres e independientes, estos condicionan su vida cotidiana, así como la celebración o conmemoración de eventos y personas a las exigencias de la producción; incluso, se tiene registro del confinamiento de los procesos de cortejo, noviazgo y amistad entre jóvenes al interior de los talleres.

3.- En el proceso de subjetivación. Las significaciones y el sentido del trabajo son aprendidos psíquica, material y prácticamente a través de la familia. Esta, como institución socializadora, transmite valores, expectativas y representaciones de la manera en que las personas perciben el trabajo y se ven a sí mismas en relación con este (Berger y Luckmann, 2001; Boso, 2012). Los ayequenses aprenden de la familia, como grupo afectivo y laboral, a pensar y ordenar la vida en torno al trabajo duro de la industria textil, y en algunos casos, a desvalorizar otras actividades laborales y de profesionalización, así como subordinar prácticas cívicas, religiosas, fúnebres, políticas, educativas, de diversión y la propia corporalidad a los tiempos y ritmos de la producción de jeans.

Aun con la centralidad del trabajo industrial en la vida de los productores de mezclilla, pueden ser entendidos como sujetos rurales con habilidades del sector secundario, considerando que los escenarios de la ruralidad contemporánea no aluden necesariamente a lo agrícola, sino a una manera de pensar el territorio, de reproducir ciertas prácticas y formas de organización, y de adscribirse identitariamente. Si bien en San Mateo Ayecac un porcentaje minúsculo de población se considera campesina, la localidad ha ido adecuándose a las transformaciones sociales y a los proyectos político-económicos del Estado y del mercado, que, lejos de velar ciertas prácticas "tradicionales", han costeado y afianzado la permanencia de estas en sus diversas expresiones: mayordomías, fiestas, comités, etcétera. 


\section{Conclusiones}

La producción de pantalones de mezclilla en San Mateo Ayecac implica una realidad compleja compuesta por un conjunto de elementos económicos, políticos, históricos y ambientales. Permite observar la forma en que ciertos sujetos rurales aprovechan la precariedad y la flexibilidad para sobrevivir y configurar sus propios modos de existencia personal y colectiva, así como la manera en que históricamente han experimentado desigualdad y vulnerabilidad al encontrarse desprotegidos de derechos y de un empleo e ingresos constantes. Empero, esto ha posibilitado que usaran los pocos recursos que poseen para, por cuenta propia, asimilar las premisas del trabajo neoliberal, al punto de emprender en una actividad como la producción de jeans.

Los productores de mezclilla son una expresión de la forma en que las poblaciones subalternas asumen la responsabilidad de sí mismas ante condiciones estructurales que escapan a su entendimiento, pero no a la experiencia de vivir y pensarse a ellos y a sus familias desdibujados de la atención del Estado y en el trabajo de reserva del sistema capitalista. Así que, una vía para no depender de estas figuras radica en asumir la producción de textiles como una actividad que pueden conducir (seleccionando, más o menos de manera condicionada, el lugar, el tiempo y las dinámicas productivas) y con la que se aseguran un ingreso económico para sobrevivir y perpetuar sus iniciativas.

La precariedad, junto con la flexibilidad como condiciones de existencia, se convierte en una oportunidad, esto es, en una arena para planificar, organizar y dirigir una economía subalterna integrada por una red de productores informales locales y regionales. Con esta lógica, ambas se han incrustado en los procesos de socialización, en el estilo de vida, y en la personalidad y actitud hacia al trabajo contemporáneo, lo que ha posibilitado la emergencia de un nuevo sujeto rural.

\section{Financiamiento:}

Esta investigación se realizó con financiamiento, en la modalidad de beca, del Consejo Nacional de Ciencia y Tecnología, CONACYT, y del Programa de Apoyo a Proyectos de Investigación e Innovación Tecnológica, PAPIIT, No. A300316, Universidad Nacional Autónoma de México.

\section{Agradecimientos:}

Agradezco a CONACYT y al PAPIIT IA300316, UNAM por el apoyo otorgado para la realización de esta investigación que forma parte de mi tesis doctoral.

\section{Biografía}

Doctora en Antropología por la Universidad Nacional Autónoma de México. Actual posdoctorante en El Colegio de Tlaxcala A.C. 


\section{Referencias bibliográficas}

》Adler, L. (1975). Cómo sobreviven los marginados. México: Siglo XXI.

»Arias, P. (2009). La pluriactividad rural a debate. En H. Carton de Grammont y L. Martínez (coords.), La pluralidad en el campo latinoamericano (pp. 171-206). Quito: Facultad Latinoamericana de Ciencias Sociales (FLACSO).

» Arjona, A. y Checa, J. C. (2006). Economía étnica. Teorías, conceptos y nuevos alcances. Revista Internacional de Sociología (RIS), 45, 117-143.

» Berger, P. y Luckmann, T. (2001). La construcción social de la realidad. Buenos Aires: Amorrortu.

"Boso, R. (2012). Reflexiones sobre el trabajo desde las experiencias laborales de jóvenes universitarios de la Ciudad de Buenos Aires. En M.L. Jiménez y R. Boso (coords.), Juventud precarizada. De la formación al trabajo, una transición riesgosa (pp. 47-78). México: Universidad Nacional Autónoma de México.

" Cuevas, H. (2015). Precariedad, precariado y precarización. Un comentario crítico desde América Latina para The precariat. The new dangerous class de Guy Standing. Polis, Revista Latinoamericana, 14(40), 313-329.

"De la Garza, E. (2006). Reestructuración productiva, empresas y trabajadores en México. México: Fondo de Cultura Económica.

"Douglas, L. y Hansen, T. (2003). Los orígenes de la industria maquiladora en México. Comercio externo, 53(11), 1045-1056.

»Dumont, G. y Clua, R. (2015). Acercamiento socio-antropológico al concepto de estilo de vida. Aposta, Revista de Ciencias Sociales, 66, 83-99.

"Freeman, C. (2007). The "reputation" of neoliberalism. American Ethnologist, 24(2), 252-267.

» Gómez, F. (2008). Cartografías de poder. Globalización y campesinos en la obra de WiIliam Roseberry. Ecuador Debate, 74, 137-154.

"González, A. (2008a). De las manos tejedoras a las fábricas textiles: el nacimiento de una industria en Tlaxcala. Tlahcuilo, 2(4), 9-24.

" González, A. (2008b). Humedales en el suroeste de Tlaxcala: agua y agricultura en el siglo $X X$. México: Universidad Iberoamericana.

》 Harvey, D. (2015). Breve historia del neoliberalismo. España: Akal.

"Instituto Nacional de Estadística y Geografía (INEGI) (2014). Directorio Estadístico Nacional de Unidades Domésticas. Recuperado de http://www.beta.inegi.org.mx/app/mapa/ denue/

» Kellet, P. y Tipple, A. G. (2000). The home as workplace: a study of income-generating activities within the domestic setting. Enviroment and Urbanization, 12(1), 203-213.

»Méndez, R. (1994). Descentralización industrial, sistemas productivos locales y desarroIlo rural. Revista EURE, 61, 57-75.

"Osorio, J. (2010). La exclusión de la lógica del capital. Migración y desarrollo, 14, 89-104.

»Paleta, G. (2014). La conformación histórico-territorial y productiva en la segunda mitad del siglo XIX. En H. Salas y L. Rivermar (eds.), Nativitas, Tlaxcala. La construcción en el tiempo de un territorio rural (pp. 59-71). México: Instituto de Investigaciones Antropológicas-Universidad Autónoma de México. 
»Portes, A. y Haller, W. (2005). The informal economy. En El manual de la sociología económica (pp. 403-425). Princeton: Princeton University Press.

» Prentice, R. (2012). “No One Ever Showed Me Nothing”: skill and self-making among trinidadian garment workers. Anthropology and Education Quartely, 43(4), 400-414.

» Prentice, R. (2015). Introduction. En Thiefing a chance. Factory work, illicit labor, and neoliberal subjectivities in Trinidad (pp. 1-23). Colorado: University Press of Colorado.

» Robinson, W. (2013). Una teoría sobre el capitalismo global, México: Siglo XXI.

» Roseberry, W. (2014). Antropologías e historias: ensayos sobre cultura, historia y economía política. Michoacán: El Colegio de Michoacán.

» Rothstein, F. (1986). The new proletarians: Third world reality and first world categories. Comparative studies in society and history, 28(2), 217-238.

»Salas, H. y Velasco, P. (2013). Los rostros rurales de la dominación en el neoliberalismo actual. Revista Márgenes, 13, 7-13.

» Salas, H., Rivermar, L. y Velasco, P. (Eds.) (2011). Nuevas ruralidades. Expresiones de la transformación social en México. México: Instituto de Investigaciones AntropológicasUniversidad Autónoma de México.

» Secretaría de Desarrollo Social (2017). Tlaxcala, Tepetitla de Lardizábal. Informe anual sobre la situación de pobreza y rezago social. Recuperado de http://diariooficial.gob.mx/ SEDESOL/2017/Tlaxcala_019.pdf

» Suárez, S. (2011). Globalización y transformaciones socioterritoriales en el ámbito rural: puntualizaciones sobre una nueva ruralidad. En H. Salas, L. Rivermar y P. Velasco (Eds.), Nuevas ruralidades. Expresiones de la transformación social en México (pp. 59-81). México: Instituto de Investigaciones Antropológicas-Universidad Autónoma de México.

»Vallejo, J. (2016). Talleres de mezclilla y transformaciones en un municipio rural. El caso de Tepetitla de Lardizábal, Tlaxcala, México. Sociedad y ambiente, 4(11), 68-91.

»Velasco, P. (2014a). Antropología socioambiental. Ecología política, sujetos rurales y transformación del río Atoyac en el municipio de Nativitas, Tlaxcala (Tesis doctoral), Universidad Nacional Autónoma de México, Ciudad de México, México.

»Velasco, P. (2014b). Repensando el pasado agrícola para entender el presente rural. En H. Salas y L. Rivermar (Eds.), Nativitas, Tlaxcala La construcción en el tiempo de un territorio rural (pp. 115-13). México: Instituto de Investigaciones Antropológicas-Universidad Autónoma de México.

» Velasco, P. (2017). Deshilando etnográficamente la mezclilla: materialidad y entramados socioambientales paradójicos. Alteridades, 27(54), 95-106. 